\title{
Effects of nonesterified fatty acids on the synthesis and assembly of very low density lipoprotein in bovine hepatocytes in vitro
}

\author{
Lei Liu, ${ }^{\star 1}$ Xinwei Li, ${ }^{* 1}$ Yu Li, ${ }^{* 1}$ Yuan Guan, † Yuxiang Song, ${ }^{*}$ Liheng Yin, ${ }^{*}$ Hui Chen, ${ }^{*}$ Liancheng Lei, ${ }^{*}$ \\ Juxiong Liu, ${ }^{*}$ Xiaobing Li, ${ }^{*}$ Zhe Wang, ${ }^{*}$ Xiaoyu Yang, $\ddagger^{2}$ and Guowen Liu ${ }^{* 2}$ \\ *Key Laboratory of Zoonosis, Ministry of Education, College of Veterinary Medicine, Jilin University, 5333 Xi'an Road, Changchun, Jilin, 130062 , \\ China \\ †College of Animal Science, Jilin University, 5333 Xi'an Road, Changchun, Jilin, 130062, China \\ ¥Department of Orthopedics, China-Japan Union Hospital, Jilin University, 130033, China
}

\begin{abstract}
High serum concentrations of nonesterified fatty acids (NEFA), which may affect the synthesis and assembly of very low density lipoproteins (VLDL), are associated with fatty liver during the early lactation period. Therefore, the objective of this study was to investigate the effects of NEFA on the synthesis and assembly of VLDL in bovine hepatocytes. Bovine hepatocytes were cultured and treated with different concentrations of NEFA. The mRNA expression of apolipoprotein B100 $(A p o B 100)$ and apolipoprotein $\mathrm{E}(A p o E)$ was significantly lower in the NEFA treatment groups than in the control group ( $0 \mathrm{~m} M \mathrm{NEFA})$. The abundance of mRNA from microsomal triglyceride transfer protein $(M T P)$ and the low density lipoprotein receptor $(L D L R)$ was significantly lower in the medium- and high-dose NEFA treatment groups. The protein expression of ApoB100, ApoE, MTP, and LDLR was found to be significantly and dose-dependently decreased in groups of NEFA-treated hepatocytes. The VLDL content was also significantly decreased in the NEFA-treated hepatocytes. Large amounts of triglycerides accumulated in the hepatocytes. These results indicate that NEFA significantly inhibits the expression of ApoB100, ApoE, $M T P$, and $L D L R$, thereby decreasing the synthesis and assembly of VLDL and inducing TG accumulation in bovine hepatocytes.
\end{abstract}

Key words: bovine hepatocyte, nonesterified fatty acids, very low density lipoprotein, in vitro

\section{INTRODUCTION}

Fatty liver is a major lipid metabolic disorder of dairy cows in early lactation and is associated with decreased

\footnotetext{
Received February 2, 2013.

Accepted November 7, 2013.

${ }^{1}$ These authors contributed equally to this study.

${ }^{2}$ Corresponding authors: yangxiaoyu88@sina.com and liuguowen2008 @163.com
}

health status and reproductive performance. In dairy cows, fatty liver occurs primarily in the first $4 \mathrm{wk}$ after calving (Grummer, 1993), when up to $50 \%$ of all dairy cows exhibit some accumulation of triglycerides (TG) in the liver (Jorritsma et al., 2000, 2001). The natural incidence of fatty liver is significantly higher in ruminant animals than in monogastric animals, which is due to the special metabolic characteristics of ruminants. During the early lactation period, most dairy cows experience a negative energy balance (NEB) caused by the increased demand for energy to support milk production (Friggens et al., 2007; Xu et al., 2008). This NEB initiates fat mobilization and a subsequent increase in NEFA blood concentration (Grummer, 2008). In addition, dairy cows have a very slow rate of secretion of hepatic very low density lipoproteins (VLDL) compared with most species (Pullen et al., 1990).

A high concentration of blood NEFA plays a pivotal role in the pathogenesis of fatty liver syndrome (Jorritsma et al., 2001; Zhang et al., 2011). Nonesterified fatty acids are esterified into TG when uptake exceeds oxidation capacity for NEFA in the hepatocytes. Therefore, fatty liver occurs when the rate of hepatic TG synthesis exceeds the rate of TG disappearance through either hydrolysis or secretion via VLDL (van Dorland et al., 2011). Apolipoprotein B100 (ApoB100), apolipoprotein $\mathrm{E}(A p o E)$, microsomal triglyceride transfer protein $(M T P)$, and low density lipoprotein receptor $(L D L R)$ are the main structural and regulatory proteins for the synthesis and assembly of VLDL (Mason, 1998; Greenow et al., 2005).

Several studies have demonstrated that NEFA can act as signaling molecules involved in regulating the expression of lipid metabolism genes (Duplus et al., 2000; Jump et al., 2005). High serum concentrations of NEFA are associated with the fatty liver of dairy cows. Therefore, we hypothesized that NEFA could affect the synthesis and assembly of VLDL in bovine hepatocytes. The objective of this study was to investigate the effects of NEFA on the synthesis and assembly of VLDL in bovine hepatocytes cultured in vitro. 


\section{MATERIALS AND METHODS}

\section{Materials}

Fetal bovine serum, collagenase IV, and RPMI-1640 medium were purchased from Gibco (Grand Island, New York, NY). Oleic acid, linoleic acid, palmitic acid, stearic acid, palmitoleic acid, insulin, and HEPES were purchased from Sigma Aldrich (St. Louis, MO). Dexamethasone acetate, vitamin $\mathrm{C}$, ascorbic acid, penicillin, streptomycin, and other chemicals were provided by Baoman Biotechnology (Shanghai, China).

\section{Reagents and Solutions}

Perfusion solution A comprised $140 \mathrm{mM} \mathrm{NaCl}, 6.7$ $\mathrm{m} M \mathrm{KCl}, 10 \mathrm{~m} M$ HEPES, $2.5 \mathrm{~m} M$ glucose, and $0.5 \mathrm{~m} M$ EDTA. The solution $\mathrm{pH}$ was adjusted to 7.4. Perfusion solution B comprised $140 \mathrm{~m} M \mathrm{NaCl}, 6.7 \mathrm{mM} \mathrm{KCl}, 30$ $\mathrm{m} M$ HEPES, $2.5 \mathrm{~m} M$ glucose, and $5 \mathrm{mM} \mathrm{CaCl}$. The solution $\mathrm{pH}$ was adjusted to 7.4. For digestion, $0.1 \mathrm{~g}$ of collagenase IV was dissolved in $0.5 \mathrm{~L}$ of perfusion solution B. The RPMI-1640 basic culture medium was prepared according to the manufacturer's protocol, and comprised $26 \mathrm{mM} \mathrm{NaHCO}$, $10 \mathrm{~m} M$ HEPES, and 20 $\mathrm{m} M \mathrm{NaCl}$. The solution $\mathrm{pH}$ was adjusted to 7.2 . The adherent medium consisted of RPMI-1640 basic medium supplemented with $10 \%$ fetal calf serum, $10^{-6} \mathrm{M}$ insulin, $10^{-6} M$ dexamethasone, $10 \mu \mathrm{g} / \mathrm{mL}$ vitamin $\mathrm{C}$, $100 \mathrm{U} / \mathrm{mL}$ benzylpenicillin, and $100 \mu \mathrm{g} / \mathrm{mL}$ streptomycin. The growth medium consisted of RPMI-1640 basic medium supplemented with $10 \%$ fetal calf serum, 100 $\mathrm{U} / \mathrm{mL}$ benzylpenicillin, and $100 \mu \mathrm{g} / \mathrm{mL}$ streptomycin. Phosphate buffer solution comprised $137 \mathrm{mM} \mathrm{NaCl}, 2.7$ $\mathrm{m} M \mathrm{KCl}, 10 \mathrm{~m} M \mathrm{Na}_{2} \mathrm{HPO}_{4}$, and $1.8 \mathrm{~m} M \mathrm{KH}_{2} \mathrm{PO}_{4}$. The $\mathrm{pH}$ of PBS solution was adjusted to 7.4. Tris-buffered saline and Tween buffer solution comprised $10 \mathrm{mM}$ Tris. $\mathrm{HCl}, 150 \mathrm{~m} \mathrm{M} \mathrm{NaCl}$, and $0.1 \%$ Tween-20. The solution $\mathrm{pH}$ was adjusted to 7.4 .

\section{Cell Culture}

The study protocol was approved by the Ethics Committee on the Use and Care of Animals of Jilin University (Changchun, China). The caudate liver lobe of a dairy cow was obtained through surgical liver excision according to a previous study (Parker and Gaughan, 1988). The dairy cow was positioned in left lateral recumbency. General anesthesia was maintained with thiamylal sodium. A $20-\mathrm{cm}$ right abdominal incision was made from the costal margin. The skin, muscle layers, and peritoneum were incised. Self-retaining retractors were placed in the incision. The caudate lobe of the liver was excised. Subsequently, fibrin glue was sprayed on the hepatic cross section. The hepatic cross section was sutured immediately. The incision was closed in 3 layers (peritoneum, abdominal muscle, and skin). After surgery, the dairy cow was carefully nursed to prevent inflammation and infection.

The hepatocytes were isolated by the collagenase perfusion method. The caudate lobe of the liver was quickly moved to a super-clean bench. The bloodstains on the liver surface were removed with perfusion solution $\mathrm{A}\left(37^{\circ} \mathrm{C}\right)$. Blood vessels were intubated, and the liver was perfused with perfusion solution $\mathrm{A}$ at a flow rate of $50 \mathrm{~mL} / \mathrm{min}$ for $15 \mathrm{~min}$. The liver was then perfused with perfusion solution $\mathrm{B}\left(37^{\circ} \mathrm{C}\right)$ at the same flow rate until the liquid became clear. Then, the liver was perfused with digestion solution to dissociate liver tissue structure over $15 \mathrm{~min}$ until the liquid became muddy. The liver was moved to a sterile flat plate after digestion, and $100 \mathrm{~mL}$ of basic medium $\left(4^{\circ} \mathrm{C}\right)$ containing $0.2 \% \mathrm{BSA}$ was added into the flat plate to terminate the digestion. The liver was cut open, and the liver capsule, blood vessels, fat, and connective tissue were removed using forceps and scissors. The liver parenchyma was cut into pieces and filtered sequentially with 100 mesh $(150 \mu \mathrm{m}), 200$ mesh $(75 \mu \mathrm{m})$, and 400 mesh $(37.5 \mu \mathrm{m})$ cell sieves. The hepatocyte suspension was washed twice with basic medium and centrifuged for 10 min at $500 \times g$ at $4^{\circ} \mathrm{C}$. The Trypan blue dye exclusion method was used to assess cell viability. The percentage of viable cells was almost $99 \%$. The cell density was adjusted to $1 \times 10^{6}$ cells $/ \mathrm{mL}$ using adherent medium. The hepatocyte suspension was seeded into a 6 -well tissue culture plate $(2 \mathrm{~mL}$ per well). The hepatocytes were incubated at $37^{\circ} \mathrm{C}$ in $5 \% \mathrm{CO}_{2}$. After $4 \mathrm{~h}$, the adherent medium was replaced with growth medium containing $10 \%$ fetal bovine serum. The growth medium was replaced every $24 \mathrm{~h}$.

\section{NEFA Preparation and Treatment}

The composition and concentration of NEFA used in this study were chosen according to the hematology standards of dairy cows with fatty liver (Bertics et al., 1992). Stock NEFA solution was prepared as previously described (Li et al., 2012). Briefly, oleic acid (10.875 $\mathrm{mmol})$, linoleic acid $(1.225 \mathrm{mmol})$, palmitic acid (7.975 mmol), stearic acid (3.6 mmol), and palmitoleic acid $(1.325 \mathrm{mmol})$ were dissolved in $100 \mathrm{~mL}$ of potassium hydroxide solution $(1 \mathrm{M})$ at $60^{\circ} \mathrm{C}$. The $\mathrm{pH}$ of the NEFA solution was adjusted to 7.6 with hydrochloric acid (1 $M$ ), and then the solution was diluted to $500 \mathrm{~mL}$ with distilled water. Therefore, the concentration of stock NEFA solution was $50 \mathrm{~m} M$, containing $21.75 \mathrm{~m} M$ oleic acid, $15.95 \mathrm{~m} M$ palmitic acid, $7.2 \mathrm{~m} M$ stearic acid, 2.65 $\mathrm{m} M$ palmitoleic acid, and $2.45 \mathrm{~m} M$ linoleic acid. 
Table 1. Primer sequences $($ For $=$ forward; Rev $=$ reverse $)$ of the genes

\begin{tabular}{|c|c|c|c|}
\hline Gene & Primers used for PCR & $\begin{array}{l}\text { Length of } \\
\text { fragment (bp) }\end{array}$ & $\begin{array}{c}\text { Annealing } \\
\text { temperature }\left({ }^{\circ} \mathrm{C}\right)\end{array}$ \\
\hline ApoB100 & $\begin{array}{l}\text { For: GATACTCAGAACGGAGCAAT } \\
\text { Rev: GCACCAATCAGATAACAGGA }\end{array}$ & 223 & 60 \\
\hline ApoE & $\begin{array}{l}\text { For: TCCTGAATGACCTGGGTGTTG } \\
\text { Rev: TCTGTGGGTTGCCGTGGTG }\end{array}$ & 217 & 60 \\
\hline$M T P$ & $\begin{array}{l}\text { For: CAGTTTGCAGCCTTGGTTCTG } \\
\text { Rev: TCTGTGGGTTGCCGTGGTG }\end{array}$ & 201 & 60 \\
\hline$L D L R$ & $\begin{array}{l}\text { For: GCT GTT CTG CCT TTC TCC TT } \\
\text { Rev: ACT TTC TCC CCT GAC CCT TG }\end{array}$ & 228 & 60 \\
\hline$A C T B$ & $\begin{array}{l}\text { For: GCCCTGAGGCTCTCTTCCA } \\
\text { Rev: GCGGATGTCGACGTCACA }\end{array}$ & 101 & 60 \\
\hline
\end{tabular}

The basic medium was supplemented with $3.8 \%$ BSA. Before treatment with NEFA solvent, the cells were starved of serum overnight. The stock NEFA solution was added to the basic medium. The hepatocytes were treated with $0 \mathrm{~m} M$ NEFA (control group), $0.5 \mathrm{~m} M$ NEFA (low-dose group), $1.0 \mathrm{~m} M$ NEFA (medium-dose group), or $1.5 \mathrm{mM}$ NEFA (high-dose group) for $24 \mathrm{~h}$. Hepatocytes were treated with different concentrations of NEFA and with different concentrations of $\mathrm{KCl}$. In an additional experiment, hepatocytes were treated with $0,2,4$, or $6 \mathrm{mM} \mathrm{KCl}$ and treated for $24 \mathrm{~h}$. Each treatment concentration of NEFA or $\mathrm{KCl}$ was replicated 12 times.

\section{RNA Extraction and PCR}

Total hepatic RNA was extracted using TRIzol (TaKaRa Biotechnology Co. Ltd., Dalian, China) according to the manufacturer's instructions. Total RNA was dissolved in diethylpyrocarbonate water. Five microliters of RNA solution was used to detect its concentration using a Gene Quant II RNA/DNA Calculator (Pharmacia Biotech, Cambridge, UK). The RNA in all samples was diluted to the same concentration using diethylpyrocarbonate water. Approximately $5 \mu \mathrm{g}$ of RNA in each sample was reverse transcribed to cDNA in $20-\mu \mathrm{L}$ reactions using a reverse transcription kit (TaKaRa Biotechnology Co. Ltd.), according to the supplier's protocol. The gene primers were designed using Primer 5.0 (PE Applied Biosystems Inc., Foster, $\mathrm{CA}$ ) and are shown in Table 1 . The concentration of the primer was $10 \mu M$. The annealing temperature of ApoB100, ApoE, MTP, LDLR, and ACTB were all $60^{\circ} \mathrm{C}$. The mRNA expression was evaluated by quantitative reverse transcription-PCR (qRT-PCR) analysis using the SYBR Green QuantiTect RT-PCR Kit (TaKaRa Biotechnology Co. Ltd.). The qRT-PCR was performed on a 7500 Real-Time PCR System (Applied Biosystems). The relative expression of genes was calculated by the $2^{-\Delta \Delta \mathrm{CT}}$ method and was normalized to abundance of $\beta$-actin (Livak and Schmittgen, 2001).

\section{Western Blotting}

Hepatocytes were harvested and washed twice in ice-cold PBS. The total cell protein was extracted using a protein extraction kit (Sangon Biotech Co. Ltd. Shanghai, China) according to the manufacturer's instructions. The protein concentration was measured using BioRad protein assay reagent (Bio-Rad, München, Germany). The protein was separated in polyacrylamide gels and electro-transferred onto polyvinylidene difluoride (PVDF) membranes. The membranes were blocked in BSA-Tris-buffered saline-Tween buffer for $4 \mathrm{~h}$. The concentrations of BSA and Tween were 5 and $0.1 \%$, respectively. The membranes were hybridized with antibodies specific for ApoB100, ApoE, MTP, and LDLR at dilutions of 1:500, 1:500, 1:500, and 1:1,000, respectively, overnight at $4^{\circ} \mathrm{C}$. The $\mathrm{ApoB} 100$ and ApoE antibodies are goat polyclonal antibodies and react with ApoB100 and ApoE of bovine origin (Abcam, Cambridge, UK; cat. no. ab7616 and ab20261). The MTP and LDLR antibodies are affinity-purified goat polyclonal antibodies raised against a peptide mapping at the N-terminus of MTP and C-terminus of LDLR of bovine origin, respectively (Santa Cruz Biotechnology, Santa Cruz, CA; cat. no. H1407 and L3008). The PVDF membranes were incubated with appropriate peroxidase-conjugated secondary antibodies at dilutions of 1:5,000, 1:5,000, 1:4,000, and 1:4,000. Immunoreactive bands were detected with enhanced chemiluminescence solution (Beyotime Biotechnology Inc., Haimen, China). The blots were exposed to x-ray film for radiography of the bands, and the gray values of the bands were measured using BandScan software version 5.0 (ProZyme Inc., San Leandro, CA).

\section{Determination of VLDL Content}

The medium from the 6 -well plates was collected after NEFA treatment. The content of VLDL synthesized and secreted by hepatocytes was determined using ELISA kits (Shanghai Bluegene Biotech Co. Ltd., 
Shanghai, China; cat. no. E11V0006), according to the manufacturer's protocol. All the samples were assayed in duplicate.

\section{Determination of TG Content}

The cell medium was removed using a micropipettor. Hepatocytes were harvested using a cell scraper and transferred into a centrifuge tube. Then, the cells were washed twice with ice-cold PBS. The cells were lysed using lysis buffer (Shanghai Bluegene Biotech Co. Ltd.) in ice bath conditions for $30 \mathrm{~min}$. Subsequently, the lysate was centrifuged for $5 \mathrm{~min}$ at $12,000 \times \mathrm{g}$ at $4^{\circ} \mathrm{C}$, and the supernatant was used to determine the content of triglycerides with a commercial kit (TOOS0929; Applygen Technologies Inc., Beijing, China) using an automatic biochemical analyzer (Shenyang EKSV Medical Equipment Co. Ltd., Shenyang, China).

\section{Statistical Analysis}

The results are expressed as the mean \pm standard deviation (SD). The data were analyzed by a one-way ANOVA followed by Duncan's multiple range test (SPSS 13.0 software; SPSS Inc., Chicago, IL). A $P$ value of $<0.05$ was considered statistically significant, and values $<0.01$ were considered markedly significant.

\section{RESULTS}

\section{Expression Abundance of Genes Involved in VLDL Assembly}

We observed no significant difference in the mRNA expression of ApoB100, ApoE, MTP, or LDLR between $\mathrm{KCl}$-treated groups and the control group. In addition, we observed no difference in VLDL content among the treatment groups and no statistical significance between groups. These results demonstrated that $\mathrm{KCl}$ did not markedly affect the synthesis and assembly of VLDL in bovine hepatocytes (Figure 1).

The mRNA abundance of $A p o B 100$ and ApoE in NEFA-treated groups was significantly lower than that of the control group $[P<0.05$ and $P<0.01$ for ApoB (Figure 2A); $P<0.01$ for ApoE (Figure 2B)]. The mRNA abundance of $M T P$ and $L D L R$ in the medium- and high-dose NEFA treatment groups was significantly lower than that of the control group (Figure 2C, 2D; $P<0.01$ for both MTP and LDLR). The protein expression of ApoB100, ApoE, MTP, and LDLR was found to be significantly and dosedependently decreased in all groups of NEFA-treated hepatocytes (Figure 2E).

\section{VLDL and TG Content}

The VLDL content was found to be significantly and dose-dependently decreased in all groups of NEFAtreated hepatocytes compared with the control hepatocytes $(P<0.05$ and $P<0.01$ for VLDL content; Figure 3 ). The TG content was found to be significantly and dose-dependently increased in all groups of NEFA-treated hepatocytes compared with the control hepatocytes $(P<0.05$ and $P<0.01$ for TG content; Figure 4).

\section{DISCUSSION}

Fatty liver is usually associated with a pronounced NEB at the beginning of lactation in high-yielding dairy cows. A high concentration of plasma NEFA has many pathological consequences. Cameron et al. (1998) reported that a high plasma concentration of NEFA was a risk factor for the induction of ketosis and fatty liver in dairy cows. Fatty liver may develop when the rate of TG synthesis exceeds the rate of TG export as VLDL (Bernabucci et al., 2004). Sevinc et al. (2003) reported that the serum content of VLDL was significantly decreased in dairy cows with fatty liver. Therefore, in the present study, hepatocytes were cultured and treated with different concentrations of NEFA. The stock NEFA solution included $\mathrm{KCl}$. The results of the additional experiment showed that $\mathrm{KCl}$ did not affect expression of ApoB100, ApoE, MTP, or LDLR, or VLDL assembly. The effect of NEFA on VLDL assembly was investigated in hepatocytes treated with different concentrations of NEFA.

Triglycerides are combined with apolipoprotein and exported from hepatocytes as VLDL. A clinical study demonstrated that synthesis and secretion of VLDL are significantly decreased in the liver of dairy cows with fatty liver (Katoh, 2002), which may due to the high concentration of NEFA. The proteins ApoB100 and ApoE are the most important structural components of VLDL; ApoB100 is the TG-binding protein in VLDL and is necessary for stabilizing the VLDL particles (Bernabucci et al., 2004). A study revealed that the nascent VLDL particles acquired ApoE during the assembly cascade (Mensenkamp et al., 2001). Uchida et al. (1992) demonstrated that the plasma concentration of ApoB100 in the dairy cows with fatty liver was significantly lower than that of healthy cows. In addition, Mensenkamp et al. (2001) reported that the secretion of VLDL-TG was severely impaired in ApoE-deficient mice. In the present study, the mRNA and protein expression of ApoB100 and ApoE were significantly lower in NEFA-treated groups than in the control group. 

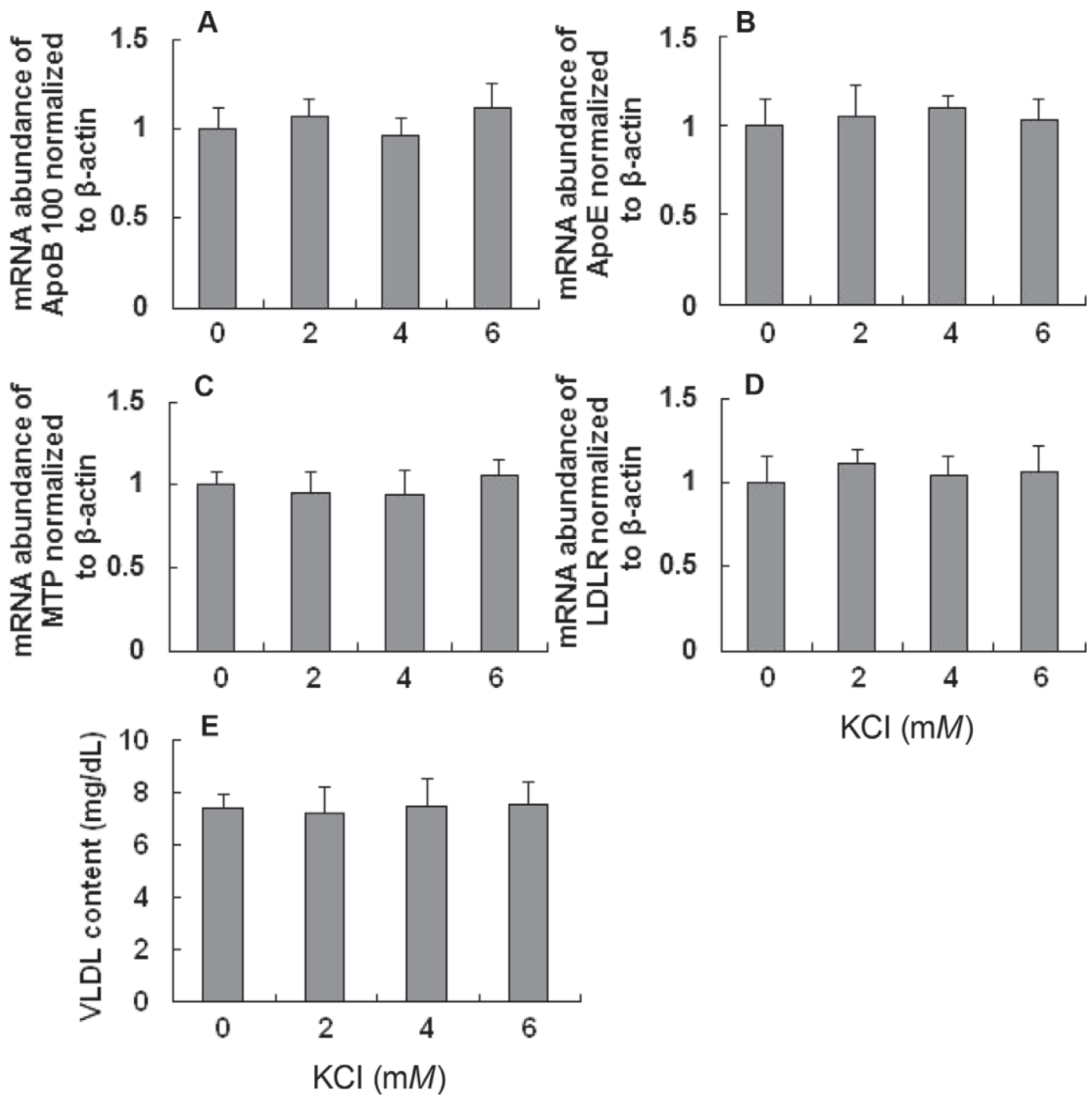

Figure 1. The mRNA expression of ApoB100, ApoE, MTP, and $L D L R$ and very low density lipoprotein (VLDL) content in the KCl-treated bovine hepatocytes. The hepatocytes were treated with 0,2 , 4 , or $6 \mathrm{mM} \mathrm{KCl}$. Each treatment concentration of $\mathrm{KCl}$ was replicated 12 times.

These results indicate that a high concentration of NEFA inhibits the expression of ApoB100 and ApoE in bovine hepatocytes. Dairy cows experience a negative energy balance, which subsequently induces a high concentration of blood NEFA. Large amounts of NEFA were esterified into TG in hepatocytes. Furthermore, high concentrations of NEFA affected the synthesis of VLDL. Our in vitro study also demonstrated that NEFA inhibited the expression of ApoB100 and ApoE in hepatocytes, thereby decreasing the structural components of VLDL.

Both MTP and LDLR are important regulatory proteins for the synthesis of VLDL; MTP is responsible for the transport of TG into the growing VLDL particles, resulting in the formation of nascent lipoprotein particles (Sundaram and Yao, 2010), whereas LDLR inhibits the secretion of ApoB100 and regulates the assembly of VLDL (Read et al., 2000). Bremmer et al. (2000) found no relationship between the degree of fatty liver and the activity of MTP in dairy cows. However, our in vitro data demonstrated that the abundance of MTP was significantly lower in the NEFAtreated hepatocytes than in the control hepatocytes. A deficiency of MTP reduced the combination between TG and apolipoprotein. The discrepancy between our results and those of previous studies may be due to the effects of the energy metabolic hormones and nutrition metabolic signals such as insulin, glucagon, and BHBA in vivo. To our knowledge, no data are available on the changes of mRNA and protein expression of $L D L R$ in dairy cows with fatty liver. In this study, the mRNA and protein expression of $L D L R$ was significantly lower 

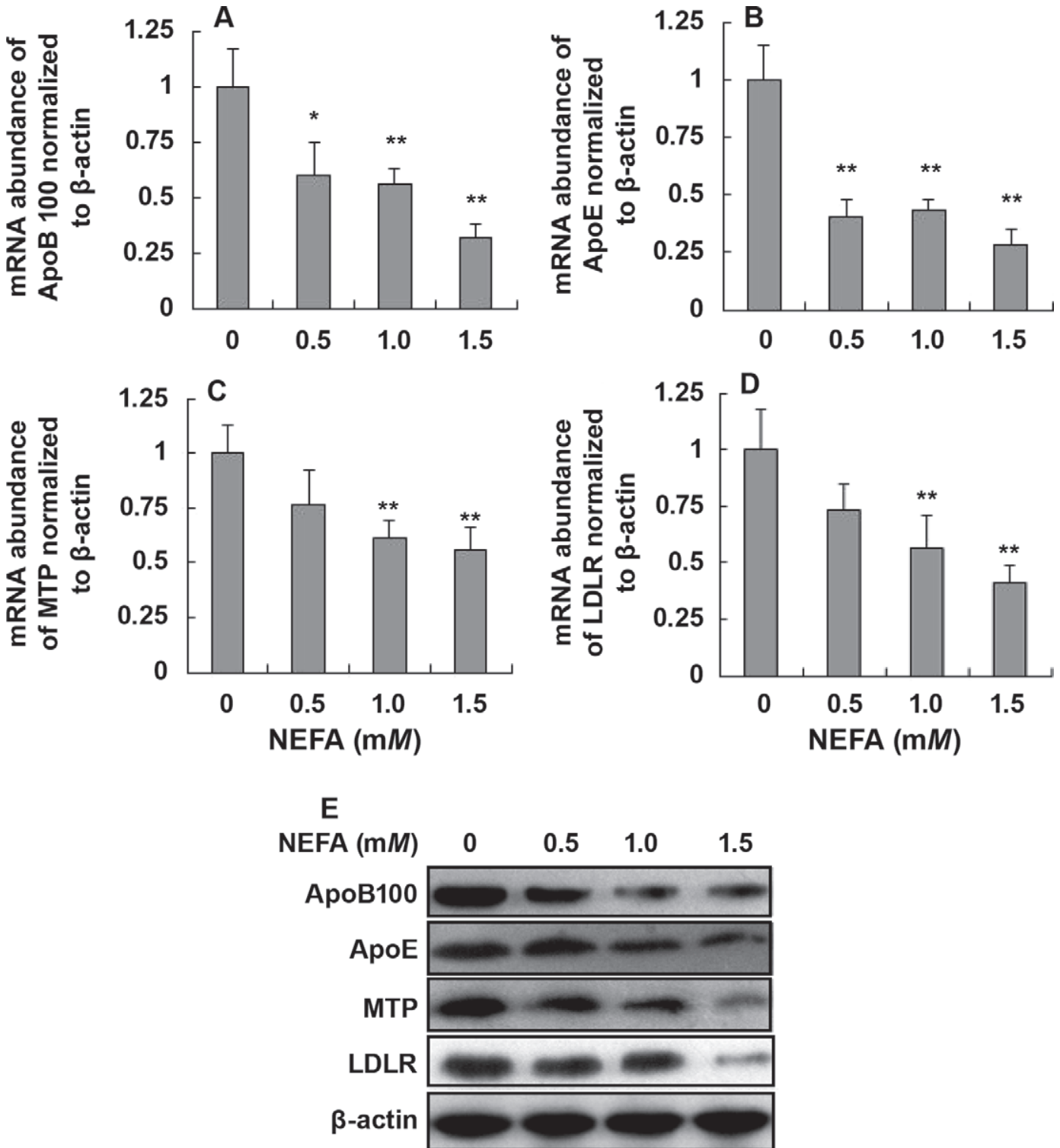

Figure 2. The mRNA and protein expression of ApoB100, ApoE, MTP, and LDLR in the NEFA-treated bovine hepatocytes. The hepatocytes were treated with $0 \mathrm{~m} M$ NEFA (control group), $0.5 \mathrm{~m} M$ NEFA (low-dose group), $1.0 \mathrm{~m} M$ NEFA (medium-dose group), and $1.5 \mathrm{~m} M$ NEFA (high-dose group). (A) mRNA expression of ApoB100; (B) mRNA expression of ApoE; (C) mRNA expression of MTP; (D) mRNA expression of $L D L R$; (E) Western blot results of ApoB100, ApoE, MTP, and LDLR. Each treatment concentration of NEFA was replicated 12 times. ${ }^{*} P$ $<0.05,{ }^{*} P P<0.01$ compared with the control group.

in the NEFA-treated groups than in the control group, which indicates that NEFA inhibits the expression of $L D L R$. A low abundance of LDLR results in an increase of ApoB100 secretion from hepatocytes, thereby decreasing the structural components of VLDL. Taken together, with the decreased expression of ApoB100, ApoE, MTP, and LDLR, the synthesis and assembly of VLDL were significantly decreased in the NEFA-treated hepatocytes. Consequently, a large amount of TG accumulated in the hepatocytes and the TG content was significantly higher in the NEFA-treated hepatocytes than in the control hepatocytes.
Our results confirm that a high concentration of NEFA is an important pathogenic factor for accumulation of TG in hepatocytes; NEFA inhibited the synthesis and assembly of VLDL. Unfortunately, dairy cows have a very slow rate of VLDL export from the liver; thus, the capacity of that route of NEFA disposal is easily exceeded. Therefore, a high concentration of NEFA accentuates the accumulation of TG in hepatocytes. In clinical application, increasing VLDL export is the most effective strategy to treat fatty liver in dairy cows. Choline, methionine, and glucagon are used for the prevention and treatment of fatty liver. An in 


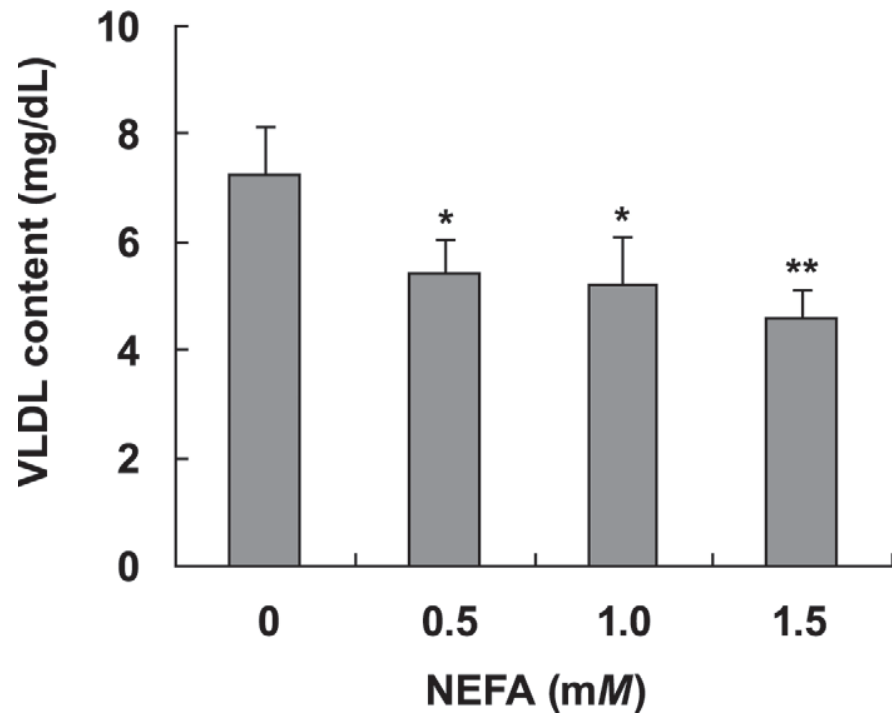

Figure 3. Content of very low density lipoprotein (VLDL) in the NEFA-treated hepatocytes. The hepatocytes were treated with $0 \mathrm{mM}$ NEFA (control group), $0.5 \mathrm{~m} M$ NEFA (low-dose group), $1.0 \mathrm{~m} M$ NEFA (medium-dose group), and $1.5 \mathrm{~m} M$ NEFA (high-dose group) Each treatment concentration of NEFA was replicated 12 times. ${ }^{*} P<$ $0.05,{ }^{* *} P<0.01$ compared with the control group.

vivo study demonstrated that choline and methionine could enhance VLDL export from the liver (Grummer, 1993). Cooke et al. (2007) reported that choline deficiency could increase the accumulation of $\mathrm{TG}$ in

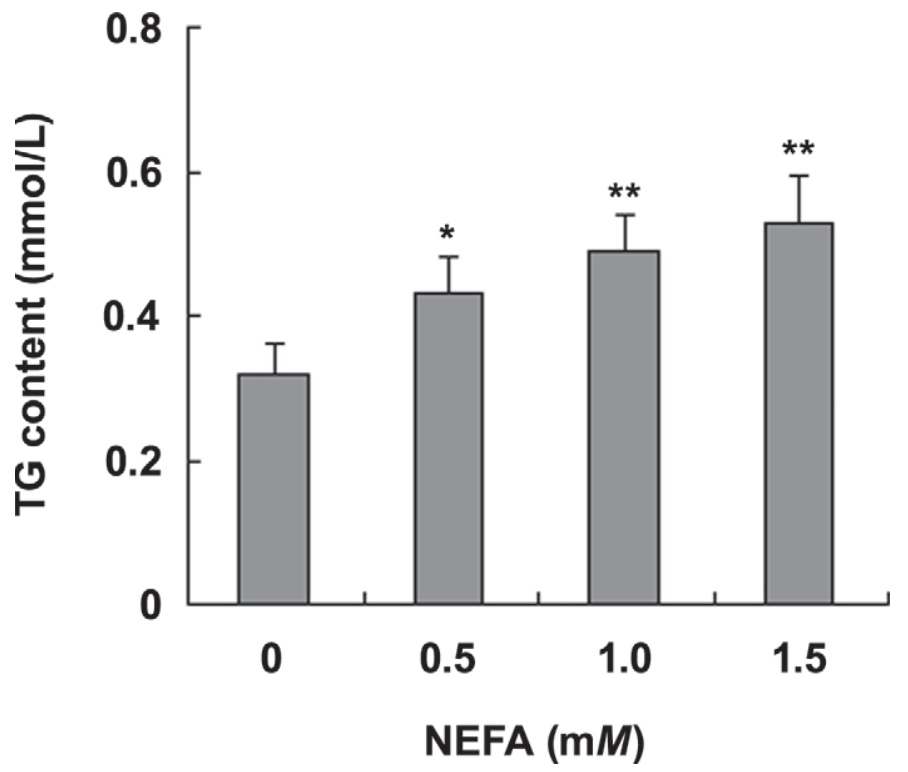

Figure 4. Content of triglycerides (TG) in the NEFA-treated hepatocytes. The hepatocytes were treated with $0 \mathrm{~m} M$ NEFA (control group), $0.5 \mathrm{~m} M$ NEFA (low-dose group), $1.0 \mathrm{~m} M$ NEFA (medium-dose group), and $1.5 \mathrm{~m} M$ NEFA (high-dose group). Each treatment concentration of NEFA was replicated 12 times. ${ }^{*} P<0.05,{ }^{* *} P<0.01$ compared with the control group. liver. Choline serves as a substrate for the synthesis of phosphatidylcholine, a constituent of VLDL (Cooke et al., 2007). Methionine is required for the synthesis of protein (a constituent of VLDL) and as a methyl donor for phosphatidylcholine synthesis (Bauchart et al., 1998). Glucagon stimulates hepatic glycogenolysis, gluconeogenesis, and insulin production. Glucagon has an effect of reducing liver TG content in dairy cows with fatty liver (Nafikov et al., 2006). Therefore, an increase of VLDL synthesis is critical in preventing fatty liver in dairy cows.

\section{CONCLUSIONS}

A high concentration of NEFA significantly inhibited the expression of ApoB100, ApoE, MTP, and LDLR, thereby decreasing the synthesis and assembly of VLDL and inducing TG accumulation in bovine hepatocytes.

\section{ACKNOWLEDGMENTS}

This study was supported by the Program for New Century Excellent Talents in University (NCET-110199), the National Key Technology R\&D Program (Grant No. 2012BAD12B03), the National Natural Science Foundation of China (Beijing, China; Grant Nos. 30871897, 31072178, 31172372, 31272621), and the Science Fund for Distinguished Young Scholars of Jilin University (Grant No. 201100009).

\section{REFERENCES}

Bauchart, D., D. Grffat, and Y. Chilliard. 1998. Mechanism of liver steatosis in early lactation cows-Effects of hepatoprotector agents. Pages 27-37 in Proc. Cornell Nutr. Conf., Cornell University, Ithaca, NY.

Bernabucci, U., B. Ronchi, L. Basiricò, D. Pirazzi, F. Rueca, N. Lacetera, and A. Nardone. 2004. Abundance of mRNA of apolipoprotein $\mathrm{B}_{100}$, apolipoprotein $\mathrm{E}$, and microsomal triglyceride transfer protein in liver from periparturient dairy cows. J. Dairy Sci. $87: 2881-2888$

Bertics, S. J., R. R. Grummer, C. Cadorniga-Valino, and E. E. Stoddard. 1992. Effects of prepartum dry matter intake on liver triglyceride concentration and early lactation. J. Dairy Sci. 75:19141922.

Bremmer, D. R., S. J. Bertics, S. A. Besong, and R. R. Grummer. 2000. Changes in hepatic microsomal triglyceride transfer protein and triglyceride in periparturient dairy cattle. J. Dairy Sci. $83: 2252-2260$.

Cameron, R. E. B., P. B. Dyk, T. H. Herdt, J. B. Kaneene, R. Miller, H. F. Bucholtz, J. S. Liesman, M. J. Vandehaar, and R. S. Emery. 1998. Dry cow diet, management, and energy balance as risk factors for displaced abomasum in high producing dairy herds. J. Dairy Sci. 81:132-139.

Cooke, R. F., N. Silva Del Rio, D. Z. Caraviello, S. J. Bertics, M. H. Ramos, and R. R. Grummer. 2007. Supplemental choline for prevention and alleviation of fatty liver in dairy cattle. J. Dairy Sci. 90:2413-2418.

Duplus, E., M. Glorian, and C. Forest. 2000. Fatty acid regulation of gene transcription. J. Biol. Chem. 275:30749-30752.

Friggens, N. C., C. Ridder, and P. Løvendahl. 2007. On the use of milk composition measures to predict the energy balance of dairy cows. J. Dairy Sci. 90:5453-5467. 
Greenow, K., N. J. Pearce, and D. P. Ramji. 2005. The key role of apolipoprotein E in atherosclerosis. J. Mol. Med. (Berl.) 83:329-342.

Grummer, R. R. 1993. Etiology of lipid-related metabolic disorders in periparturient dairy cows. J. Dairy Sci. 76:3882-3896.

Grummer, R. R. 2008. Nutritional and management strategies for the prevention of fatty liver in dairy cattle. Vet. J. 176:10-20.

Jorritsma, R., H. Jorritsma, Y. H. Schukken, and G. H. Wentink. 2000. Relationships between fatty liver and fertility and some periparturient diseases in commercial Dutch dairy herds. Theriogenology 54:1065-1074.

Jorritsma, R. H., Y. H. Schukken, P. C. Bartlettd, T. Wensinga, and G. H. Wentink. 2001. Prevalence and indicators of postpartum fatty infiltration of the liver in nine commercial dairy herds in The Netherlands. Livest. Prod. Sci. 68:53-60.

Jump, D. B., D. Botolin, Y. Wang, J. Xu, B. Christian, and O. Demeure. 2005. Fatty acid regulation of hepatic gene transcription. J. Nutr. 135:2503-2506.

Katoh, N. 2002. Relevance of apolipoproteins in the development of fatty liver and fatty liver-related peripartum diseases in dairy cows. J. Vet. Med. Sci. 64:293-307.

Li, X., X. Li, G. Bai, H. Chen, Q. Deng, Z. Liu, L. Zhang, G. Liu, and Z. Wang. 2012. Effects of non-esterified fatty acids on the gluconeogenesis in bovine hepatocytes. Mol. Cell. Biochem. 359:385388.

Livak, K. J., and T. D. Schmittgen. 2001. Analysis of relative gene expression data using real-time quantitative PCR and the $2^{-\triangle \Delta C T}$ method. Methods 25:402-408.

Mason, T. M. 1998. The role of factors that regulate the synthesis and secretion of very-low-density lipoprotein by hepatocytes. Crit. Rev. Clin. Lab. Sci. 35:461-487.

Mensenkamp, A. R., L. M. Havekes, J. A. Romijn, and F. Kuipers. 2001. Hepatic steatosis and very low density lipoprotein secretion: The involvement of apolipoprotein E. J. Hepatol. 35:816-822.

Nafikov, R. A., B. N. Ametaj, G. Bobe, K. J. Koehler, J. W. Young, and D. C. Beitz. 2006. Prevention of fatty liver in transition dairy cows by subcutaneous injections of glucagon. J. Dairy Sci. 89:1533-1545.
Parker, J. E., and E. M. Gaughan. 1988. Partial hepatic resection for treatment of a single liver abscess in a dairy heifer. Vet. Surg. $17: 87-89$

Pullen, D. L., J. S. Liesman, and R. S. Emery. 1990. A species comparison of liver slice synthesis and secretion of triacylglycerol from nonesterified fatty acids in media. J. Anim. Sci. 68:1395-1399.

Read, J., T. A. Anderson, P. J. Ritchie, B. Vanloo, J. Amey, D. Levitt, M. Rosseneu, J. Scott, and C. C. Shoulders. 2000. A mechanism of membrane neutral lipid acquisition by the microsomal triglyceride transfer protein. J. Biol. Chem. 275:30372-30377.

Sevinc, M., A. Basoglu, and H. Guzelbektas. 2003. Lipid and lipoprotein levels in dairy cows with fatty liver. Turk. J. Vet. Anim. Sci. 27:295-299.

Sundaram, M., and Z. Yao. 2010. Recent progress in understanding protein and lipid factors affecting hepatic VLDL assembly and secretion. Nutr. Metab. (Lond.) 7:35. http://dx.doi. org/10.1186/1743-7075-7-35.

Uchida, E., N. Katoh, and K. Takahashi. 1992. Induction of fatty liver in cows by ethionine administration and concomitant decreases of serum apolipoproteins B-100 and A-I concentrations. Am. J. Vet. Res. 53:2035-2042

van Dorland, H. A., H. Sadri, I. Morel, and R. M. Bruckmaier. 2011. Coordinated gene expression in adipose tissue and liver differs between cows with high or low NEFA concentrations in early lactation. J. Anim. Physiol. Anim. Nutr. 96:137-147. http://dx.doi. org/10.1111/j.1439-0396.2011.01130.x.

Xu, C., Z. Wang, G. W. Liu, X. B. Li, G. H. Xie, C. Xia, and H. Y. Zhang. 2008. Metabolic characteristic of the liver of dairy cows during ketosis based on comparative proteomics. Asian-australas. J. Anim. Sci. 21:1003-1010.

Zhang, Z., X. Li, G. Liu, L. Gao, C. Guo, T. Kong, H. Wang, R. Gao, Z. Wang, and X. Zhu. 2011. High insulin concentrations repress insulin receptor gene expression in calf hepatocytes cultured in vitro. Cell. Physiol. Biochem. 27:637-640. 